\title{
Obesity in Print: An Analysis of Daily Newspapers
}

\author{
Anja Hilbert Jens Ried \\ Department of Psychology, Philipps University of Marburg, Germany
}

\section{Key Words}

Stigmatization - Weight stigma - Media - Newspapers . Content analysis

\section{Summary}

Background: Stigmatizing attitudes towards obese people are common in the public. Based on findings that portrayals of obesity in entertainment media foster weight-related stigmatization, the goal of the current study was to analyze media coverage of obesity in daily newspapers. Methods: For the year 2006, all 1,563 issues of five high-circulation daily newspapers (two national newspapers, one tabloid newspaper, and two local newspapers) in Germany were systematically searched for obesity-related terms. Out of these issues, 222 articles about human overweight were identified and subjected to a quantitative content analysis using a reliable coding system. Results: The national and local newspapers examined offered more comprehensive and less incorrect information about obesity than the tabloid newspaper. Compared with the other types of papers, the information about obesity in the local papers was less negative and less catastrophizing. The national newspapers presented more attributions of obesity to internal, controllable causes than the other newspaper types, and the tabloid newspaper used more personalized descriptions of cases with extreme features. Conclusion: The current coverage of obesity in daily newspapers may contribute to stigmatization. Future research should examine readers' reception of newspaper information and potential destigmatization through more precise and less subjective coverage of obesity.

\section{Introduction}

Stigmatizing attitudes towards obese people are common in Western industrialized countries [1,2]. Exposure to weight stigma is associated with lower health in vulnerable obese individuals $[3,4]$ and may complicate the detrimental effects of excess body fat on medical morbidity and mortality [5, 6]. As media representations of obesity in entertainment media have been found to foster weight-related stigmatization [7-11], the goal of the current study was to determine the coverage of obesity in information media, with a focus on daily newspapers.

The mass media have been suspected of being at least partly responsible for the development, spread, and maintenance of weight stigma $[10,11]$. The promotion of a cultural thinness ideal might not only have contributed to a negative perception of obese people in the public but also to their negative self-perception [12]. Moreover, the general public is not wellinformed regarding the definition, prevalence, and causes of obesity [13]. Subjective or simplistic information, for example the idea that body weight is completely under individual control, could foster misconceptions and give rise to stigmatization [2]. In general, media coverage shapes public opinion and thereby supports specific attitudes or behaviors [14], for example, regarding health $[15,16]$.

Previous investigations of media representations of obesity and obese people have focused on media primarily used for entertainment purposes. As demonstrated by several previous content analyses of television shows or movies, obese individuals, particularly obese women, were presented in a negative and stereotyped way, ridiculed, and excluded from specific types of social interactions [7-9]. In the print media, exposure to before-after pictures that advertised diets in women's magazines increased negative views of obese people and the readers' assumption of the individual controllability of body

\begin{tabular}{ll}
\hline KARGER & $\oplus$ 2009 S. Karger GmbH, Freiburg \\
Fax +497614520714 & Accessible online at: \\
Information@Karger.de & www.karger.com/ofa \\
www.karger.com &
\end{tabular}


weight [10]. In fact, the amount of time 10- to 13-year-olds spend reading magazines was associated with the extent they devalued obese children of the same age [11]. While these data suggest that entertainment media support weight-related stigmatization, the coverage of obesity in information media such as daily newspapers remains largely unclear. Previous content analyses of newspaper articles and television news have focused on attributions of personal responsibility and gathered inconsistent evidence on the proportion of individualistic versus societal attributions of obesity [17-19]. Clearly, based on the public deficits regarding information about obesity and the stigmatizing potential of the media coverage, a comprehensive analysis of information about obesity in media such as daily newspapers is warranted. Daily newspapers are commonly thought to be highly credible and relevant in informing the public and shaping opinions [14].

In this context, the goal of the current study was to investigate the coverage of obesity in daily German newspapers. Specifically, the comprehension and adequacy of the newspaper content were analyzed in regards to the definition, etiology, prevalence, medical co-morbidity, psychosocial consequences, treatment, and prevention of obesity. In addition, the subjective evaluation of obesity was determined by examining catastrophizing, negative, or stigmatizing information about obesity and use of personalized accounts conveying extreme features. It was hypothesized that national newspapers would inform their readers more comprehensively and objectively about obesity than local or tabloid newspapers. The latter were assumed to report in a more catastrophizing, negative, stigmatizing, and personalized way when compared to the other types of newspapers. As local newspapers are often read for practical advice, they were expected to provide more information about the treatment and prevention of obesity.

\section{Material and Methods}

\section{Sample}

Five high-circulation daily newspapers from Germany were selected for the study: i) the two largest national newspapers, the Süddeutsche Zeitung (circulation of approximately 445,000 copies per day) and the Frankfurter Allgemeine Zeitung (ca. 400,000); ii) the largest tabloid newspaper, the Bild-Zeitung (ca. 3,400,000); and iii) the two local newspapers from the location where the work was conducted, the Marburger Neue Zeitung (ca. 79,000 ) and the Oberhessische Presse (ca. 31,000).

For the time period of the study, the year 2006, all 1,563 copies of these newspapers were subjected to a systematic search on obesity-related terms (national newspapers: 603 issues; local: 565; tabloid: 304). Specifically, the titles of all newspaper articles were searched for the keywords of: overweight, obesity/obese, adiposity/adipose, excess body fatness/fat, fatness/fat, big, corpulence/corpulent, massive, chubby, plump, compact, gluttony, binge eating, bulimia, craving, pounds, kilo, nutrition, diet, body weight, weight, weight loss/reduction/management/maintenance/gain, eating/nutrition behavior, food intake, meal, feast, binge, snack, slim/slim down, slender, lose weight, fasting, physical activity, exercise, movement/ move, or similar. Articles that only focused on topics other than human overweight were excluded from the study sample.
Through the systematic search, 222 newspaper articles on human overweight were identified for the study sample. Out of these 222 articles, 90 articles were from the national newspapers (40.5\%), 97 articles were from the local newspapers $(43.7 \%)$, and 35 articles were from the tabloid newspaper $(15.8 \%)$. There were no differences in the mean number of obesity-related articles by newspaper type (Kruskal-Wallis $\chi^{2}$ test, $\chi^{2}(2$, $\mathrm{N}=3)=2.00, \mathrm{p}=0.368)$. Newspaper types differed by the number of words per article $\left(\chi^{2}(2, \mathrm{~N}=222)=69.98,38.02, \mathrm{p}<0.01\right)$; pairwise post-hoc comparisons indicated a larger number of words per article in the national newspapers than in the local newspapers, and articles from both of these newspaper types were longer than those of the tabloid newspaper (all $\mathrm{p}<$ $0.01 ; 404.43 \pm 355.08$ words per article, $251.48 \pm 214.34,117.17 \pm 107.78)$.

\section{Dependent Variables}

All dependent variables were defined in a coding system guiding the quantitative content analysis [20,21] of the newspaper articles. The coding system included precise definitions of variables and examples. It was developed on the basis of rational and empirical criteria, the latter of which was derived from a pilot study on a sample of 33 obesity-related articles from the year 2005. All variables were developed using state-of-the-art knowledge about obesity, such as the clinical guidelines of the Deutsche Adipositas-Gesellschaft [22], current epidemiological data [23, 24], recent textbooks, research summaries, and reviews [e.g. 5, 6, 25, 26].

As described in table 1, the coding system included the content and evaluative variables, and an additional variable of formal salience. The content variables summarized the amount of information (number of information units) within each article about the definition, prevalence, etiology, co-morbidity, psychosocial consequences, treatment, and prevention of obesity. In addition, three higher-order content variables were derived: comprehensiveness, defined as the amount of information coded within the above-mentioned content variables; scope, defined as number of the coded content variables; and the amount of unambiguously incorrect information as compared with current empirical evidence (false information). The evaluative variables served to assess the amount of information (number of information units) within each article about catastrophization and devaluation (including stigmatization), internal attribution, and personalization (including a report of extreme features). Further, pictures that belonged to the identified articles and focused on human overweight were analyzed for subjective evaluation using a five-point rating scale ranging from $-2=$ very negative to $+2=$ very positive. To formally characterize the article, an index of salience was developed in which the placement of the article in the newspaper (title page, $0=$ no, $1=$ yes), placement of the page $(0=$ lower half, $1=$ upper half $)$, accentuation through colors/typography $(0=$ no, $1=$ yes $)$, and use of pictures $(0=$ no, $1=$ yes $)$ was rated and aggregated to a sum score $(0-4)$.

The quantitative content analysis was conducted by one rater. In order to determine interrater reliability of coding, an independent rater, blind to study hypotheses, coded one third of randomly chosen articles by newspaper type (overall $\mathrm{N}=77$ ). The correlations between both ratings were highly significant $($ all $\mathrm{p}<0.01)$. The content variables yielded a mean interrater correlation of Kendall's $\tau_{\mathrm{b}}=0.94(0.87-0.98)$, the evaluative variables a mean $\tau_{\mathrm{b}}=0.91(0.81-0.97)$, and the formal salience index a mean $\tau_{\mathrm{b}}=0.89$. In addition to the correlations that display the strength of associations between the ratings, the exact percentage interrater agreement was determined. For the content variables, the coding of both raters was identical in $83.7 \%$ of the articles $(72.7-94.8 \%$ ), for the evaluative variables in $82.1 \%(67.6-97.4 \%)$, and for the salience index in $81.9 \%$ of the articles.

\section{Data Analytic Plan}

Data analysis was based on the absolute amount of information for each variable (or index information of the salience index) and included nonparametric Kruskal-Wallis $\chi^{2}$ tests because of non-normal distributions. In addition, because of differences in the length of the articles by newspa- 
Table 1. Coding scheme for the quantitative content analysis: Variables, definitions, and coding

Variable Definition Coding

\section{Content Variables}

Definition

Prevalence

Etiology

Comorbidity

Psychosocial consequences

Treatment

Prevention

Comprehensiveness

Scope

False information
Definition of excess body fat, BMI classification of adults and of children/adolescents

Example: 'Obesity is defined as a body mass index greater than 30 .'

Prevalence rates for adults, children, and adolescents; variations according to gender, social class, or ethnicity, etc.; increase of prevalence rates Example: 'Every fifth child in Germany is overweight.'

Multifactorial etiology; genetic, environmental/behavioral factors; other markers, e.g., pregnancy Example: 'School breaks with coke and pizza.'

Increased risk for medical morbidity and mortality Example: 'Overweight Americans die earlier.'

Adverse effects on psychological well-being, quality of life, stigmatization, and discrimination

Example: 'Many people suffer psychologically from their increased weight.'

Indication, goals, settings, interventions, outcome of treatment Example: 'Almost all people gain their weight back after several years.'

Definition, goals, settings, interventions, outcome, and societal relevance of prevention

Example: 'Prevention measures serve to stop the obesity epidemic from childhood on.'

Number of information units across content variables, including definition, prevalence, etiology, comorbidity, psychosocial consequences, treatment, and prevention

Number of coded content variables

Unambiguously incorrect information given the evidence

Example: 'With that diet you will never be obese again.' $\mathrm{n}$ information units

$\mathrm{n}$ information units

$\mathrm{n}$ information units

$\mathrm{n}$ information units

$\mathrm{n}$ information units

$\mathrm{n}$ information units

$\mathrm{n}$ information units

total information units

$\mathrm{n}$ content variables

$\mathrm{n}$ information units
Evaluative Variables

Catastrophization

Devaluation

Stigmatization

Internal attribution

Personalization

Extreme Features

Evaluative illustrations
Presentation of obesity and the associated consequences in a dramatic way Example: 'We are too fat - and that will kill us.'

Negative naming or description of overweight/obese people or overweight/obesity Example: 'Hiring freeze for fatties'

Attribution of negative characteristics to overweight/obese people Example: 'They are often lacking self-discipline.'

Statements in which an overweight/obese person is held responsible for being overweight or for being unsuccessful in managing weight

Example: 'Many Germans become overweight because they just eat what they like.'

Names, portrayals, quotations of and interviews with overweight/obese persons Example: 'Horst F. moved his 112 kg upstairs.'

Extreme characteristics of individual cases, e.g., extreme obesity, extreme medical or psychosocial consequences, extreme comparisons such as before-after comparisons

Example: 'She is so heavy that she cannot leave her house anymore.'

Rating of evaluation within illustrations of overweight/obese people $\mathrm{n}$ information units

$\mathrm{n}$ information units

n information units

$\mathrm{n}$ information units

$\mathrm{n}$ cases

$\mathrm{n}$ information units

$-2=$ very negative

to $+2=$ very positive
Formal Aspects

Salience
Location of article in issue (title page, $0=$ no, $1=$ yes), location of article on page

$(0=$ lower half of page, $1=$ upper half of page $)$, highlighting by coloring or

typography $(0=$ no, $1=$ yes $)$, illustration $(0=$ no, $1=$ yes $)$

total of features $(0-4)$ 
Table 2. Obesity-related content and evaluative tendencies in German newspapers in 2006: a comparison of daily newspapers, local newspapers, and a tabloid newspaper*

\begin{tabular}{|c|c|c|c|c|c|c|c|c|c|c|c|c|}
\hline & \multicolumn{6}{|c|}{ Newspapers } & \multicolumn{6}{|l|}{$\chi^{2}$} \\
\hline & \multicolumn{2}{|c|}{$\begin{array}{l}\text { national } \\
(\mathrm{n}=90)\end{array}$} & \multicolumn{2}{|c|}{$\begin{array}{l}\text { local } \\
(\mathrm{n}=97)\end{array}$} & \multicolumn{2}{|c|}{$\begin{array}{l}\text { tabloid } \\
(\mathrm{n}=35)\end{array}$} & \multicolumn{3}{|c|}{$\begin{array}{l}\text { Numbers of information } \\
\text { units }\end{array}$} & \multicolumn{3}{|c|}{ Proportions } \\
\hline & mean & SD & mean & $\mathrm{SD}$ & mean & SD & $(\mathrm{df}=2)$ & $\mathrm{p}$ & post hoc & $(\mathrm{df}=2)$ & $\mathrm{p}$ & post hoc \\
\hline \multicolumn{13}{|l|}{ Content } \\
\hline Definition, $\mathrm{n}$ & 0.33 & 1.05 & 0.23 & 1.06 & 0.06 & 0.34 & 2.89 & 0.236 & & 2.66 & 0.264 & \\
\hline Prevalence, $\mathrm{n}$ & 2.08 & 3.13 & 0.97 & 2.32 & 0.54 & 1.17 & 17.61 & $<0.001$ & $a, b$ & 10.80 & 0.005 & $\mathrm{a}$ \\
\hline Etiology, n & 4.34 & 6.59 & 1.96 & 3.47 & 1.23 & 2.38 & 10.23 & 0.006 & $\mathrm{a}, \mathrm{b}$ & 4.16 & 0.125 & \\
\hline Comorbidity, n & 1.53 & 3.22 & 0.86 & 2.31 & 0.17 & 0.51 & 9.30 & 0.010 & $\mathrm{~b}$ & 7.35 & 0.025 & $\mathrm{~b}$ \\
\hline \multicolumn{13}{|l|}{ Psychosocial } \\
\hline consequences, $\mathrm{n}$ & 2.29 & 5.73 & 0.71 & 2.63 & 0.54 & 1.29 & 6.21 & 0.045 & $\mathrm{a}$ & 5.96 & 0.051 & \\
\hline Treatment, $\mathrm{n}$ & 3.38 & 7.55 & 5.72 & 9.20 & 3.00 & 4.76 & 7.36 & 0.025 & $\mathrm{a}$ & 14.37 & $<0.001$ & $\mathrm{a}, \mathrm{b}$ \\
\hline Prevention, $\mathrm{n}$ & 2.72 & 5.30 & 1.45 & 3.21 & 0.11 & 0.40 & 13.90 & 0.001 & $\mathrm{~b}, \mathrm{c}$ & 11.11 & 0.004 & $\mathrm{~b}, \mathrm{c}$ \\
\hline \multicolumn{12}{|l|}{ Comprehensiveness, } & \\
\hline $\begin{array}{l}\text { Scope, } \mathrm{n} \text { content } \\
\text { variables coded }\end{array}$ & 2.70 & 1.53 & 2.06 & 1.55 & 1.54 & 0.92 & 19.16 & $<0.001$ & $\mathrm{a}, \mathrm{b}$ & 11.36 & 0.003 & $\mathrm{~b}, \mathrm{c}$ \\
\hline False information, n & 0.88 & 0.78 & 0.86 & 0.75 & 1.46 & 0.89 & 15.13 & 0.001 & $\mathrm{~b}, \mathrm{c}$ & 41.98 & $<0.001$ & $\mathrm{~b}, \mathrm{c}$ \\
\hline \multicolumn{13}{|l|}{ Evaluation } \\
\hline Catastrophization, $\mathrm{n}$ & 2.14 & 3.22 & 0.79 & 1.56 & 1.34 & 1.35 & 16.22 & $<0.001$ & $\mathrm{a}, \mathrm{c}$ & 23.55 & $<0.001$ & $\mathrm{a}, \mathrm{b}, \mathrm{c}$ \\
\hline Devaluation, n & 1.81 & 3.00 & 0.86 & 1.56 & 1.77 & 2.72 & 7.99 & 0.018 & $\mathrm{a}, \mathrm{c}$ & 12.17 & 0.002 & $\mathrm{~b}, \mathrm{c}$ \\
\hline Stigmatization, $\mathrm{n}$ & 0.56 & 1.72 & 0.14 & 0.66 & 0.26 & 0.66 & 4.24 & 0.120 & & 8.80 & 0.012 & $\mathrm{a}, \mathrm{b}$ \\
\hline Internal attribution, $\mathrm{n}$ & 0.41 & 0.86 & 0.25 & 0.82 & 0.09 & 0.37 & 9.60 & 0.008 & $a, b$ & 3.37 & 0.186 & \\
\hline Personalization, $\mathrm{n}$ & 0.36 & 0.72 & 0.21 & 0.41 & 0.51 & 0.51 & 11.46 & 0.003 & $\mathrm{~b}, \mathrm{c}$ & 13.82 & $<0.001$ & $\mathrm{~b}, \mathrm{c}$ \\
\hline Extreme features, n & 0.77 & 1.51 & 0.46 & 1.03 & 1.46 & 1.77 & 11.87 & 0.003 & $\mathrm{~b}, \mathrm{c}$ & 13.11 & 0.001 & $\mathrm{~b}, \mathrm{c}$ \\
\hline $\begin{array}{l}\text { Evaluative illustrations } \\
\qquad(-2 \text { to }+2)\end{array}$ & \multicolumn{2}{|c|}{ Evaluative illustrations } & 0.14 & 1.10 & -0.50 & 0.71 & 0.41 & 0.816 & & - & & \\
\hline Salience (0-4) & 1.28 & 1.07 & 1.45 & 0.95 & 1.69 & 0.93 & 4.40 & 0.111 & & - & & \\
\hline
\end{tabular}

*Displayed are numbers of information units by article. Kruskal-Wallis $\chi^{2}$ tests for numbers of information units and for proportions (information units divided by number of words per article). Mann-Whitney $U$ tests for posthoc pairwise comparisons, marked by superscripts if significant: $\mathrm{a}=$ National newspapers versus local newspapers; $\mathrm{b}=$ national newspapers versus tabloid newspaper; $\mathrm{c}=$ local newspapers versus tabloid newspaper. $\mathrm{p}<0.05$.

per types, the same analyses were conducted based on proportions, that is amount of information by article divided by the number of words by article. Mann-Whitney U tests served for post hoc comparisons. A significance level of $\alpha<0.05$ was applied to all statistical tests.

\section{Results}

Concerning the content of the articles, the results show that the two national newspapers, compared to the two other types of newspapers, offered the most comprehensive and broadest coverage on obesity $(\mathrm{p}<0.05)($ table 2$)$. In relation to the length of articles, reports in the two local papers were also broader than those in the tabloid paper (proportions, $\mathrm{p}$ $<0.05)$. The national newspapers as well as the local newspapers published less false information than the tabloid newspaper $(\mathrm{p}<0.05)$. The national newspapers reported significantly more information about the prevalence and etiology of obesity than the other types of newspapers, and also more about medical co-morbidities than the tabloid newspaper $(\mathrm{p}<0.05)$.
Moreover, in comparison to the local newspapers, the national newspapers focused more on the psychosocial consequences of obesity $(\mathrm{p}<0.05)$. Taking into account the length of articles, there were no differences in the content variables between the national and local newspapers (proportions, $\mathrm{p}>0.05$; except for prevalence, $\mathrm{p}<0.05)$. However, according to our expectations, the local newspapers provided more information about the treatment of obesity than the national newspapers $(\mathrm{p}<$ $0.05)$. In contrast, the national and local newspapers both presented more information on the prevention of obesity than the tabloid newspaper $(\mathrm{p}<0.05)$. There were no quantitative differences between the newspaper types regarding the definition of obesity $(p>0.05)$; only a few articles defined obesity $(0.21 \pm$ 0.81 information units on the definition of obesity per article). Concerning the evaluative measures, the coverage of obesity in the local newspapers was less catastrophizing and devaluative than that of the national and tabloid newspapers ( $\mathrm{p}<0.05)$. The tabloid paper presented more personalized information in terms of examples of obese individuals and focused more on 
extreme features than the other newspaper types $(\mathrm{p}<0.05)$. The national newspapers emphasized the aspect of internal attribution more frequently than the other newspaper types $(\mathrm{p}<$ $0.05)$. There were no differences between newspaper types on stigmatization, evaluative illustrations, or salience ( $p>0.05)$. Relative to the length of the articles, the tabloid newspaper published significantly more information that were presented in a catastrophizing, negative, and personalized way, including reports about cases with extreme features $(p<0.05)$.

\section{Discussion}

The current study about the media coverage of obesity in daily newspapers provided a detailed analysis of the content and subjective evaluation of obesity-related information in highcirculation German newspapers. Daily newspapers are mostly information media and are commonly ascribed high credibility. Previous investigations have found that entertainment media, especially television shows, films or series, conveyed a negative image of obesity and that exposure to such media promoted stigmatizing attitudes towards obesity [7-11]. The promotion of weight stigma through the mass media could magnify the possible detrimental impact of stigmatization on the health of vulnerable obese individuals $[3,4]$.

The results show that the coverage of obesity in daily newspapers could in fact contribute to the perpetuation or generation of stigmatizing attitudes. In particular, in comparison to the national and local newspapers included in this study, the information in the tabloid newspaper was the least comprehensive and most incorrect, and used personalized descriptions of obese cases with extreme features. In contrast, the national newspapers provided the most comprehensive and broad information, especially with regard to the prevalence and etiology of obesity. When taking into account differences in the length of the articles, the local newspapers reached a similar level of information density as the national newspapers, and they also provided more practical, relevant information about the treatment of obesity.

Despite the high-quality coverage of obesity in the national newspapers examined, several aspects warrant notice in regards to their stigmatizing potential: in these newspapers as well as in the tabloid newspaper, the amount of catastrophizing and devaluative information was greater than in the local papers examined. When considering the length of articles, however, the proportion of negative information in the national and local newspapers was lower than that in the tabloid newspaper. Further, the national newspapers that provided the most etiological information about obesity also offered the greatest absolute number of internal attributions. As formulated by attribution theory $[27,28]$, the more a stigma such as obesity is attributed to internal, controllable causes, the greater are one's negative reactions to it, including stigmatizing attitudes [2, 29, 30]. Finally, all newspaper types presented little information about the definition of obesity. It is possible that lack of precision in this regard contributes to greater stigmatization: less information about obesity, including the prevalence and significance of this condition, has been found to be associated with more stigmatizing attitudes [2]. Nevertheless, the reader's reception of newspaper content requires further research, as previously done with entertainment media [10, 11]. The short- and long-term effects of newspaper information on negative reactions, stigmatizing attitudes, and internalization of weight stigma should be evaluated [3]. Such research could also clarify variations by sociodemographic variables, including gender, age, education or contact with overweight people $[2,10]$, attitudes such as body image concerns or conservative ideologies [31], and skills including media literacy [32]. Further, it would be of merit to clarify whether newspaper information about obesity and reception of this information differ from that about other stigmatized groups, for example minority groups or individuals with mental disorders, in order to gain insight into the specificity of stigmatizing processes and their effects [27-30].

Considering the strengths and limitations of the present study, the detailed and reliable coding system that was used for content analysis is certainly among the strengths of the study. Focusing on a comprehensive analysis of print media, aimed at providing information, is novel and needed given the potential influence of media reports on weight-related stigmatization. Nevertheless, given the limited sample size in this preliminary investigation, the results remain confined to the newspapers and time period examined. For adequate generalization, it would be necessary to have the results confirmed in a larger sample of newspapers using an assessment period longer than 1 year.

The results suggest several implications for the media coverage of obesity in daily newspapers. In particular, the inadequate and negative personalized coverage within the tabloid newspaper likely contributes to stigmatizing attitudes about obesity. For higher-quality national newspapers as well, it appears important to question which and how obesity-related information is presented. Providing a definition of obesity and less emphasis on personal responsibility could help clarify that the condition is serious, complex and multifactorial, which may help limiting stigmatizing attitudes [2, 31, 33-35]. Clearly, the role that daily newspapers could assume in the reduction of weight stigma [36-38] deserves further exploration.

\section{Acknowledgement}

This study was supported by the German Federal Ministry of Education and Research (Grant 01GP0491).

\section{Disclosure}

The authors declared no conflict of interest. 


\section{References}

1 Puhl RM, Brownell KD: Bias, discrimination and obesity. Obes Res 2001;9:788-805.

$\checkmark 2$ Hilbert A, Rief W, Brähler E: Stigmatizing attitudes towards obesity in a representative population-based sample: prevalence and psychosocial determinants. Obesity 2008;16:1529-1534.

$\checkmark 3$ Puhl RM, Latner JD: Stigma, obesity, and the health of nations's children. Psychol Bull 2007;133: 557-580.

4 Puhl RM, Moss-Racusin CA, Schwartz MB: Internalization of weight bias: implications for binge eating and emotional well-being. Obesity $2007 ; 15$ : 19-23.

5 Haslam DW, James WPT: Obesity. Lancet 2005 366:1197-1209.

6 Kopelman P: Health risks associated with overweight and obesity. Obes Rev 2007;8(suppl 1):13-

7 Himes SM, Thompson JK: Fat stigmatization in television shows and movies: a content analysis. Obesity 2007;15:712-718.

8 Greenberg BS, Eastin M, Hofschire L, Lachlan K, Brownell KD: Portrayals of overweight and obese individuals in commercial television. Am J Public Health 2003;93:1342-1348.

$\checkmark 9$ Fouts G, Burggraf K: Television situation comedy: female weight, male negative comments, and audience reactions. Sex Roles 2000;42:925-932.

10 Geier AB, Schwartz MB, Brownell KD: 'Before and After' diet advertisements escalate weight stigma. Eat Weight Disord 2003;8:282-288.

11 Latner JD, Rosewall JK, Simmonds MB: Childhood obesity stigma: association with television, videogame, and magazine exposure. Body Image 2007:4:147-155.

12 Groesz LM, Levine MP, Murnen SK: The effect of experimental presentation of thin media images on body satisfaction: a meta-analytic review. Int J Eat Disord 2003:31:1-16.

13 Hilbert A, Rief W, Brähler E: What determines public support of obesity prevention? J Epidemiol Community Health 2007:61:585-590.

14 Mangold R, Vorderer P, Bente G (eds): Lehrbuch der Medienpsychologie. Göttingen, Hogrefe, 2004.
5 Aarva P, Tampere MP: Studying the striving and opposing forces in newspaper journalism: the actantial model of health promotion. Health Promot Int 2006;21:160-168.

16 Sandberg H: Information and communication in society. Acta Paediatrica 2005;94:38-39.

17 Kim SH, Willis LA: Talking about obesity: news framing of who is responsible for causing and fixing the problem. J Health Commun 2007;12:359-376.

18 Bonfiglioli CMF, Smith BJ, King LA, Chapman SF, Holding SJ: Choice and voice: obesity debates in television news. Med J Aust 2007;187:442-445.

19 Lawrence RG: Framing obesity: the evolution of news discourse on a public health issue. Harv Int $\mathbf{J}$ Press Pol 2004:9:56-75.

20 Bente G, Krämer NC: Inhaltsanalyse medialer Angebote; in Mangold R, Vorderer P, Bente G (eds): Lehrbuch der Medienpsychologie. Göttingen, Hogrefe, 2004, pp 201-227.

21 Früh W: Inhaltsanalyse. Theorie und Praxis. Konstanz, UVK, 2004.

22 Deutsche Adipositas-Gesellschaft (ed): Evidenzbasierte Leitlinie Prävention und Therapie der Adipositas. Version 2007. www.adipositas-gesellschaft.de/daten/Adipositas-Leitlinie-2007.pdf.

23 Kurth BM, Schaffrath-Rosario A: Die Verbreitung von Übergewicht und Adipositas bei Kindern und Jugendlichen in Deutschland. Ergebnisse des bundesweiten Kinder- und Jugendgesundheitssurveys (KiGGS). Bundesgesundheitsbl Gesundheitsforsch Gesundheitssch 2007;50:736-743

24 Mensink GBM, Lampert T, Bergmann E: Übergewicht und Adipositas in Deutschland 1984-2003. Bundesgesundheitsbl Gesundheitsforsch Gesundheitssch 2005;48:1348-1356.

25 Wabitsch M, Hebebrand J, Kiess W, Zwiauer K: Adipositas bei Kindern und Jugendlichen. Grundlagen und Klinik. Heidelberg, Springer, 2005.

26 Benecke A, Vogel H: Übergewicht und Adipositas. Berlin, Robert-Koch-Institut, 2003.

27 Weiner B, Perry RP, Magnusson J: An attributional analysis of reactions to stigmas. J Pers Soc Psychol 1988;55:738-748
28 Weiner B: An attributional theory of motivation and emotion. New York, Springer, 1986

29 Menec VH, Perry RP: Reactions to stigmas among Canadian students: testing an Attribution-AffectHelp Judgment Model. J Soc Psychol 1998;138:443453.

30 Martin JK, Pescosolido BA, Tuch SA: Of fear and loathing: the role of 'disturbing behavior,' labels, and causal attributions in shaping public attitudes toward people with mental illness. J Health Soc Behav 2000;41:208-223.

31 Crandall CS: Prejudice against fat people: ideology and self-interest. J Pers Soc Psychol 1994;66:882894

32 Bergsma LJ, Carney ME: Effectiveness of healthpromoting media literacy education: a systematic review. Health Educ Res 2008;23:522-542

33 Teachman BA, Gapinski KD, Brownell KD, Rawlins M, Jeyaram S: Demonstrations of implicit antifat bias: the impact of providing causal information and evoking empathy. Health Psychol 2003;22:68-

4 Puhl RM, Schwartz MB, Brownell KD: Impact of perceived consensus on stereotypes about obese people: a new approach for reducing bias. Health Psychol 2005;24:517-525.

35 Friedman JM: Modern science versus the stigma of obesity. Nat Med 2004;10:563-569.

36 Hilbert A, Ried J, Schneider D, Jüttner C, Sosna M, Dabrock P, Lingenfelder M, Voit W, Rief W, Hebebrand J: Primary prevention of childhood obesity: an interdisciplinary analysis. Obesity Facts 2008:1:16-25.

37 Miles A, Rapoport L, Wardle J, Afuape T, Duman M: Using the mass-media to target obesity: an analysis of the characteristics and reported behaviour change of participants in BBC's 'Fighting Fat, Fighting Fit' campaign. Health Educ Res 2001;16:357-372.

38 Boyce T: The media and obesity. Obes Rev 2008; 8(suppl 1):201-205. 